\title{
Zinc chelation: a metallothionein 2A's mechanism of action involved in osteosarcoma cell death and chemotherapy resistance
}

\author{
N Habel ${ }^{1,2,3,4,5}$, Z Hamidouche ${ }^{1,2}$, I Girault ${ }^{3,4,5}$, A Patiño-García ${ }^{6}$, F Lecanda ${ }^{6}$, PJ Marie ${ }^{1,2}$ and 0 Fromigué L $^{\star 3,4,5}$
}

Osteosarcoma is the most common primary tumor of bone occurring in children and adolescents. The histological response to chemotherapy represents a key clinical factor related to survival. We previously showed that statins exhibit antitumor effects in vitro, inducing apoptotic cell death, reducing cell migration and invasion capacities and strengthening cytotoxic effects in combination with standard drugs. Comparative transcriptomic analysis between control and statin-treated cells revealed strong expression of several genes, including metallothionein (MT) 2A. MT2A overexpression by lentiviral transduction reduced bioavailable zinc levels, an effect associated with reduced osteosarcoma cell viability and enhanced cell differentiation. In contrast, MT2A silencing did not modify cell viability but strongly inhibited expression of osteoblastic markers and differentiation process. MT2A overexpression induced chemoresistance to cytotoxic drugs through direct chelation of platinumcontaining drugs and indirect action on p53 zinc-dependent activity. In contrast, abrogation of MT2A enhanced cytotoxic action of chemotherapeutic drugs on osteosarcoma cells. Finally, clinical samples derived from chemonaive biopsies revealed that tumor cells expressing low MT2A levels correspond to good prognostic (good responder patients with longer survival rate), whereas high MT2A levels were associated with adverse prognosis (poor responder patients). Taken together, these data show that MT2A contributes to chemotherapy resistance in osteosarcoma, an effect partially mediated by zinc chelation. The data also suggest that MT2A may be a potential new prognostic marker for osteosarcoma sensitivity to chemotherapy.

Cell Death and Disease (2013) 4, e874; doi:10.1038/cddis.2013.405; published online 24 October 2013

Subject Category: Cancer

Osteosarcoma is the most common primary tumor of bone. The rapid development of metastatic lesions and resistance to chemotherapy remain the two major challenges responsible for the failure of treatments and poor survival rates. The standard treatment for osteosarcoma includes neoadjuvant chemotherapy, which includes a combination of cisplatin, doxorubicin and vincristine, followed by surgical resection and postoperative chemotherapy. The clinical factors influencing survival include the presence of metastasis at diagnosis and the histological response to preoperative chemotherapy. Thus, the search for novel combinatorial strategies increasing the efficacy of standard treatments represents an area of paramount clinical impact.

We previously showed that the 3-hydroxy-3-methyl-glutaryl-coenzyme $A$ reductase inhibitors statins exhibit antitumor effects on osteosarcoma cells. ${ }^{1-3}$ Our transcriptome and molecular analyses revealed that statins modulate the expression of several genes. One of them, Cyr61 conferred enhanced metastatic potential to human and murine models. ${ }^{4}$ Another statin-regulated gene identified in osteosarcoma was metallothionein (MT) $2 A$ that belongs to MTs family.
These low-molecular weight proteins (3.5-14 kDa) characterized by a very high percentage of cysteine residues (up to $30 \%)^{5}$ exhibit a high affinity for heavy metal ions and can modulate concentrations of the free physiological essential trace elements zinc and copper (reviewed in Ruttkay-Nedecky et $a l^{6}{ }^{6}$. In humans, 18 isoforms have been identified ${ }^{7,8}$ and classified in four classes that are referred as MT-I to MT-IV. The classes MT-I/II are ubiquitously expressed, whereas MTIII and IV are expressed in a tissue-restricted manner. ${ }^{9,10}$

MTs present high affinity for biological essential intracellular metals such as zinc or copper and participate in the homeostasis of these ions. ${ }^{11-13}$ They can also chelate divalent heavy metals such as cadmium, lead, mercury or platinum via the thiol groups of cysteine residues and thus help to cell detoxification and protection. ${ }^{14}$ MTs overexpression has been linked to chemoresistance in carcinoma cells, ${ }^{15}$ non-small cell lung cancer cell lines, ${ }^{16}$ tongue squamous cell carcinoma cell lines, ${ }^{17}$ gastric tumor cell lines ${ }^{18}$ or ovarian carcinoma cell lines. ${ }^{19}$ In bone tumors, although MT levels were found to be increased in sera from patients with osteosarcoma compared with healthy patients ${ }^{20}$ and in tumor biopsies compared with

\footnotetext{
${ }^{1}$ INSERM, U606, Paris F-75010, France; ${ }^{2}$ Université Paris Diderot, Sorbonne Paris Cité, Paris F-75013, France; ${ }^{3}$ INSERM, U981, Villejuif F-94805, France; ${ }^{4}$ Gustave Roussy, Villejuif F-94805, France; ${ }^{5}$ Université Paris-Sud XI, Kremlin-Bicêtre F-94270, France and ${ }^{6}$ Center for Applied Medical Research, Oncology Division, University of Navarra, Pamplona S-31080, Spain

*Corresponding author: O Fromigué, Institut de cancérologie Gustave Roussy, INSERM U981, 39 Rue Camille Desmoulins, F-94805 Villejuif, France. Tel: + 331421136 95; Fax: + 331421160 94; E-mail: olivia.fromigue@ inserm.fr

Keywords: chemoresistance; platinum; zinc; p53; bone tumor; sarcoma

Abbreviations: BrdU, 5-bromo-2'-deoxyuridine; FCS, fetal calf serum; MT, metallothionein; MTT, 3-[4,5-dimethylthiazol-2-yl]-2,5-diphenyl tetrazolium bromide; TPEN, N,N,N',N'-tetrakis-(2-pyridylmethyl)-ethylene-diamine; ZIP, Zrt- and Irt-like protein; ZnT, zinc transporter

Received 31.7.13; revised 09.9.13; accepted 13.9.13; Edited by A Finazzi-Agró
} 
non-malignant bone biopsies, ${ }^{21}$ its use as a potential marker of tumor differentiation or cell proliferation, or as a predictor of poor prognosis, remains unclear.

In this study, we therefore evaluated the role of MT isoform $2 \mathrm{~A}$ in osteosarcoma cell behavior, investigated the cell response to cytotoxic agents according to various levels of MT2A and evaluated its prognostic value for patient outcome.

\section{Results}

Atorvastatin increases the expression level of MT2A in osteosarcoma cells. We previously showed that atorvastatin modified the expression level of several genes in human osteosarcoma cells (SaOS2) as revealed by comparative transcriptomic analysis. ${ }^{4}$ The expression of MT2A was upregulated at early time point $(6 \mathrm{~h})$ and sustained up to $24 \mathrm{~h}$ (Table 1). The expression of the other isoforms of MT was not significantly modified by statin treatment at any time points. To confirm these results, RT-qPCR was performed on SaOS2 and U2OS incubated with or without $10 \mu \mathrm{M}$ atorvastatin for $24 \mathrm{~h}$ (Figure 1a). Statin supplementation induced a twofold increase in MT2A mRNA expression level compared with untreated cells. Atorvastatin supplementation also induced an increase in MT2A expression at the protein level (Figure 1b). We then evaluated the modulation of intracellular zinc concentrations in SaOS2 and U2OS cells incubated with statin. We observed a dosedependent decrease in bioavailable zinc under atorvastatin incubation (Figure 1c).

Altogether, these results indicate that atorvastatin rapidly upregulates MT2A expression in osteosarcoma cells and reduces intracellular zinc level.

MT2A overexpression modulates osteosarcoma cell viability. We generated new cell lines by transduction with an integrative lentiviral vector encoding the complete coding sequence of the MT2A (LV-MT2A). As expected, MT2A mRNA and protein levels were significantly higher in transduced cells as compared with parental cells (Figures $2 a$ and $b$ ).

Cell viability, assessed by MTT (3-[4,5-dimethylthiazol-2yl]-2,5-diphenyl tetrazolium bromide) test, was slightly reduced in MT2A-overexpressing cells compared with parental cells at all tested time points ( -15 to $-20 \%$; Figure $2 \mathrm{c}$ ). We then evaluated the percentage of viable, apoptotic and necrotic cells by cell staining with ethidium bromide and acridine orange. The number of viable cells was slightly decreased in MT2A-overexpressing cells, in both SaOS2 and U2OS cell lines (Figure 2d). We found no difference in necrotic cell number, but we observed an increase in the apoptotic cell number in MT2A-overexpressing cells as compared with parental cells (Figure $2 \mathrm{~d}$ ). Cell proliferation rate, estimated by a 5-bromo-2'-deoxyuridine (BrdU) incorporation assay, was decreased in MT2A-overexpressing cells as compared with parental cells (Figure 2e). Estimation of DNA content by flow cytometry using propidium iodide staining revealed a significant increase in sub-G0/G1 cell populations in MT2A-overexpressing cells as compared with parental cells (Figure 2f).
Among the different signaling pathways, pERK1/2, pJNK and PAKT levels were decreased in MT2A-overexpressing cells compared with parental cells, whereas pP38 levels remained unchanged (Supplementary data 1A). A gene reporter assay confirmed that MT2A overexpression reduced transcriptional activity through AP1 complex (Supplementary data 1B). Finally, the pro-apoptotic ratio bax/bcl-2 was increased in MT2A-overexpressing cells compared with parental cells (Figure $2 \mathrm{~g}$ ).

Overall, these results suggest that the overexpression of MT2A in osteosarcoma cells leads to a reduction in cell proliferation rate and an induction of apoptosis, resulting in reduced cell viability.

MT2A expression level influences osteoblastic differentiation in osteosarcoma cells. As proliferation and differentiation processes are usually interdependent, we evaluated the osteogenic potential of osteosarcoma cells modified for MT2A. We found that MT2A overexpression induced an increase in mRNA levels of osteoblastic markers such as runx2, osterix, type I collagen and alkaline phosphatase in both SaOS2 and U2OS cell lines (Supplementary data 2A). Alkaline phosphatase enzymatic activity was also upregulated in MT2A-overexpressing cells compared with parental cells, as evaluated by colorimetric assay or cytochemical staining (Supplementary data 2B and C). Matrix mineralization was increased more than twofold in MT2A-overexpressing cells compared with parental cells in both cell lines despite their different basal differentiation stage (Supplementary data 2D and E).

These data indicate that MT2A level of expression influences osteosarcoma cell differentiation toward the osteogenic lineage.

MT2A overexpression modulates osteosarcoma cell viability through zinc chelation. We then wanted to evaluate the part of zinc concentration on osteosarcoma cell viability. SaOS2 and U2OS parental cells were incubated for $48 \mathrm{~h}$ in the presence of increasing concentrations of the intracellular chelator of zinc TPEN (N,N,N',N'-tetrakis-(2pyridylmethyl)-ethylene-diamine). As expected, TPEN dosedependently decreased SaOS2 and U2OS cell viability, assessed by the MTT test (Figure 3a). These results indicate that the levels of available intracellular zinc are required for osteosarcoma cell viability.

The comparative transcriptome analyses revealed no significant modulation of mRNA expression level of zinc transporters, either zinc transporter (ZnT)/SLC30 or Zrt- and Irt-like protein (ZIP)/SLC39 families (Table 1). These data reinforce the specific role of the isoform MT2A alone.

To estimate the relative concentration of free intracellular zinc in parental and MT2A-overexpressing cells, we used a zinc-specific fluorophore (zinquin). Overexpressing MT2A resulted in a reduction of free intracellular zinc concentration (Figure 3b). Medium supplementation with $\mathrm{ZnCl}_{2}$ led to a dose-dependent increase in intracellular zinc in both parental and MT2A-overexpressing cells, but the difference observed between MT2A-overexpressing cells and parental cells was preserved regardless of extracellular zinc concentration (Figure 3b). 
Table 1 Transcripts expression level in human (SaOS2) osteosarcoma cells

\begin{tabular}{|c|c|c|c|}
\hline & Fold change after $6 \mathrm{~h}$ & Fold change after $15 \mathrm{~h}$ & Fold change after $24 \mathrm{~h}$ \\
\hline \multicolumn{4}{|c|}{ Metallothioneins family } \\
\hline MT1A & $0.97(P>0.10)$ & $0.96(P>0.10)$ & $1.10(P>0.10)$ \\
\hline MT1B & $0.97(P>0.10)$ & $0.99(P>0.10)$ & $1.48(P>0.10)$ \\
\hline MT1E & $0.97(P>0.10)$ & $1.04(P>0.10)$ & $0.89(P>0.10)$ \\
\hline MT1F & $0.97(P>0.10)$ & $1.00(P>0.10)$ & $1.14(P>0.10)$ \\
\hline MT1G & $0.97(P>0.10)$ & $1.28(P>0.10)$ & $1.42(P>0.10)$ \\
\hline MT1J & $0.97(P>0.10)$ & $0.99(P>0.10)$ & $1.04(P>0.10)$ \\
\hline MT1K & $0.97(P>0.10)$ & $1.00(P>0.10)$ & $1.05(P>0.10)$ \\
\hline MT1L & $0.97(P>0.10)$ & $1.00(P>0.10)$ & $1.07(P>0.10)$ \\
\hline MT2A & $3.25(P=0.03)^{* *}$ & $2.90(P=0.05)^{\star *}$ & $2.85(P=0.02)^{\star *}$ \\
\hline MT4 & $0.97(P>0.10)$ & $0.92(P>0.10)$ & $0.94(P>0.10)$ \\
\hline \multicolumn{4}{|l|}{ ZnT family } \\
\hline SLC30A1 & $1.07(P>0.10)$ & $1.07(P>0.10)$ & $1.02(P>0.10)$ \\
\hline SLC30A2 & $1.02(P>0.10)$ & $1.03(P>0.10)$ & $1.03(P>0.10)$ \\
\hline SLC30A3 & $0.93(P>0.10)$ & $0.98(P>0.10)$ & $0.93(P>0.10)$ \\
\hline SLC30A4 & $0.99(P>0.10)$ & $1.08(P>0.10)$ & $1.01(P>0.10)$ \\
\hline SLC30A5 & $0.95(P>0.10)$ & $0.98(P>0.10)$ & $0.97(P>0.10)$ \\
\hline SLC30A6 & $0.97(P>0.10)$ & $1.20(P>0.10)$ & $1.05(P>0.10)$ \\
\hline SLC30A7 & $0.97(P>0.10)$ & $1.01(P>0.10)$ & $0.91(P>0.10)$ \\
\hline SLC30A8 & $0.93(P>0.10)$ & $1.07(P>0.10)$ & $0.94(P>0.10)$ \\
\hline SLC30A9 & $1.07(P>0.10)$ & $0.96(P>0.10)$ & $1.05(P>0.10)$ \\
\hline SLC30A10 & $1.11(P>0.10)$ & $0.92(P>0.10)$ & $1.02(P>0.10)$ \\
\hline \multicolumn{4}{|l|}{ ZIP family } \\
\hline SLC39A1 & $0.97(P>0.10)$ & $1.07(P>0.10)$ & $0.77(P>0.50)$ \\
\hline SLC39A2 & $1.01(P>0.10)$ & $1.07(P>0.10)$ & $1.06(P>0.10)$ \\
\hline SLC39A3 & $1.00(P>0.10)$ & $0.89(P>0.10)$ & $0.93(P>0.10)$ \\
\hline SLC39A4 & $0.97(P>0.10)$ & $1.08(P>0.10)$ & $0.97(P>0.10)$ \\
\hline SLC39A5 & $1.01(P>0.10)$ & $1.01(P>0.10)$ & $1.02(P>0.10)$ \\
\hline SLC39A6 & $1.23(P>0.10)$ & $1.05(P>0.10)$ & $0.86(P>0.10)$ \\
\hline SLC39A7 & $0.81(P>0.10)$ & $0.93(P>0.10)$ & $1.24(P>0.10)$ \\
\hline SLC39A8 & $1.01(P>0.10)$ & $0.99(P>0.10)$ & $0.88(P>0.10)$ \\
\hline SLC39A9 & $1.03(P>0.10)$ & $1.30(P>0.10)$ & $0.92(P>0.10)$ \\
\hline SLC39A10 & $0.93(P>0.10)$ & $0.90(P>0.10)$ & $0.98(P>0.10)$ \\
\hline SLC39A11 & $0.97(P>0.10)$ & $1.07(P>0.10)$ & $1.18(P>0.10)$ \\
\hline SLC39A12 & $1.05(P>0.10)$ & $0.94(P>0.10)$ & $1.00(P>0.10)$ \\
\hline SLC39A14 & $0.98(P>0.10)$ & $1.09(P>0.10)$ & $1.16(P>0.10)$ \\
\hline
\end{tabular}

ZIP, Zrt- and Irt-like protein; ZnT, zinc transporter.

Cells were incubated for 6,15 or $24 \mathrm{~h}$ with/without $10 \mu \mathrm{M}$ atorvastatin. The mRNA expression level of the main families of molecules involved in zinc homeostasis was evaluated by quantitative RT-PCR. Normalized intensities of each transcript were determined for two independent experiments. Cutoffs for selection are equal to 1 for the absolute value of log2 (ratio), and to 0.05 for the $P$-value. Fold change of the ratio of atorvastatin/control is indicated. ${ }^{* \star}$ indicates $P$-value $<0.05$ versus untreated cells.

The inhibitory effect of MT2A overexpression on cell replication was dose-dependently compensated by extracellular zinc addition (Figure 3c). A supplementation with $>5 \mu \mathrm{M}$ $\mathrm{ZnCl}_{2}$ fully offset the decrease in intracellular zinc content induced by MT2A overexpression in both SaOS2 and U2OS cells. Conversely, a culture medium containing FCS pretreated with a chelating resin (chelex) led to a decrease in parental cell proliferation rate compared with normal medium (Figure 3d). The supplementation of this chelex medium with increasing concentrations of $\mathrm{ZnCl}_{2}$ gradually restored a cell proliferation rate comparable to normal medium.

Taken together, these results indicate that intracellular zinc has a major role in osteosarcoma cell viability and proliferation. These results also indicate that an overexpression of MT2A reduces intracellular zinc availability, contributing to reduced growth kinetics of these cells.

MT2A overexpression modulates cell response to cytotoxic agents. As MTs are involved in cell detoxification from heavy metals, we compared response with platinumcontaining cytotoxic agents in MT2A-overexpressing cells to parental cells. As expected, cisplatin and transplatin (less effective isomer) reduced cell viability. The overexpression of MT2A reduced the inhibitory effect of both compounds in both cell lines (Figures $4 a$ and b). In contrast, MT2A did not affect $\mathrm{SaOS} 2 \mathrm{z}$ cell response to doxorubicin or vincristine (Figure 4c). Surprisingly, overexpression of MT2A reduced the inhibitory effect of these compounds in U2OS cells (Figure 4d).

These results suggest that MT2A overexpression reduces the cellular response to anti-proliferative agents depending on the nature of the drug, such as the presence or absence of a metal ion, and depending on the cell line genotype. Indeed, the U2OS cell line encodes wild-type p53, whereas the p53 gene is entirely deleted in the SaOS2 cell line. Such mutations can induce resistance to $\mathrm{p53}$-mediated apoptosis, specially in response to cytotoxic drugs. ${ }^{22}$ We thus further evaluated p53 implication in MT2A mechanism of action, using the U2OS cell line only.

MT2A modulates p53 conformation-dependent activity. The presence of a zinc ion is required for DNA binding and 


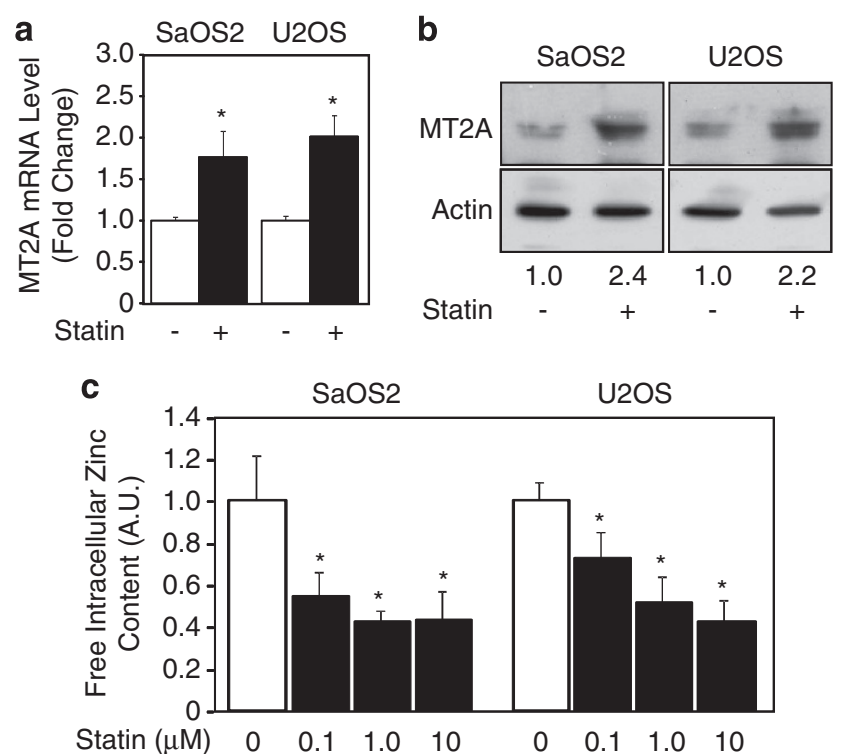

Figure 1 Atorvastatin increases MT2A expression in osteosarcoma cells. SaOS2 and U2OS cells were incubated in the presence or absence of atorvastatin $(10 \mu \mathrm{M})$ for $24 \mathrm{~h}$. (a) MT2A mRNA levels were evaluated by RT-qPCR. (b) MT2A and housekeeping gene $\beta$-actin protein levels were assessed by western blot analysis. (c) Free intracellular zinc content was evaluated by fluorimetry. Results are expressed as mean \pm S.D. ${ }^{*} P<0.05$ versus untreated cells

maintaining of an active conformation of p53 protein. We observed a lower proportion of the active form of p53 in MT2A-overexpressing U2OS cells compared with parental cells, whereas the total p53 protein level was not affected (Figure 5a). Overexpression of MT2A also reduced p21 protein level in osteosarcoma cells as compared with parental cells (Figure $5 b$ ). Overexpression of MT2A did not affect TAp73 and p63 protein levels (Figures $5 c$ and d). Supplementation of parental cells with doxorubicin led to an increase in MT2A protein level (Figure $5 \mathrm{e}$ ) and to a reduced proportion of active p53 (Figure 5f).

These results suggest that MT2A overexpression modifies p53 protein conformation, reducing its antitumor activity and then reducing cytotoxic action of doxorubicin.

MT2A silencing amplifies osteosarcoma cell response to cytotoxic agents. Next, we evaluated the effect of MT2A silencing on U2OS cells. Cell transduction with lentiviral vector led to reduced MT2A mRNA and protein levels (Figures $6 \mathrm{a}$ and b). In contrast to MT2A overexpression, we did not detect changes in cell viability, apoptosis or proliferation rate between MT2A-silenced cells and control cells (data not shown). However, MT2A silencing increased free intracellular zinc concentration compared with U2OS control cells (Figure $6 \mathrm{c}$ ), confirming that MT2A modulates the intracellular levels of bioavailable zinc.

We also found that MT2A silencing reduced mRNA levels of the osteoblastic markers runx2, osterix, type I collagen and alkaline phosphatase in both SaOS2 and U2OS cell lines (Supplementary data 3A). Alkaline phosphatase enzymatic activity and matrix mineralization were decreased in MT2Asilenced cells compared with control cells (Supplementary data $3 \mathrm{~B}-\mathrm{E}$, respectively), confirming that MT2A influences osteoblastic cell differentiation.

We then evaluated the cell response to chemotherapy drugs containing platinum or not. MT2A silencing amplifies the inhibitory effect of all tested cytotoxic compounds on U2OS cell viability (Figure 6d). Cytotoxic activity of doxorubicin correlates with the amount of drug incorporated into DNA. MT2A silencing results in an increased level of doxorubicin combined with DNA, whereas MT2A overexpression markedly reduced the amount of DNA-incorporated doxorubicin (Figure 6e). An indirect evaluation was also performed by the measure of Hoechst 33342 amount, a nuclear stain used as a post treatment to doxorubicin. It confirmed that MT2A level influences doxorubicin amount incorporated into DNA (Figure 6f).

Altogether, these results suggest that MT2A silencing in osteosarcoma cells does not significantly affect cell viability but can enhance sensitivity to drugs such as doxorubicin by facilitating its interaction with DNA.

Prognostic value of MT2A mRNA expression in osteosarcoma. Finally, we evaluated MT2A mRNA level in biopsies collected from osteosarcoma patients before any chemotherapy treatment. Post-treatment responses were scored and were linked to RT-qPCR results. We observed that MT2A mRNA level was significantly lower in good responder group than in poor/non-responder group $(P<0.0001$; statistical test power $=0.9991$; Figure 7a). Estimated mean disease-free survival rates were calculated using Kaplan-Meier's method (Figure 7b). For the low MT2A group, the mean survival time was $>120$ months and for the high MT2A responder group, the mean survival time was 37 months $(P<0.05)$.

These data suggest that MT2A mRNA level evaluated at diagnostic could be of prognostic value for chemotherapy response in osteosarcoma, discriminating between good and poor responders.

\section{Discussion}

MTs are known to be involved in detoxification process, masking or neutralizing drugs and promoting cell survival. ${ }^{23}$ Our present data show that the MT2A protein level influences free intracellular zinc ion content in osteosarcoma cells. Importantly, we provide evidence that metal chelation by MT2A controls cell proliferation, survival and differentiation. More importantly, MT2A expression levels also modulate chemoresistance to some cytotoxic drugs. Our data indicate that the mechanism of action is dependent not only on the presence or absence of a metal ion in the cytotoxic compound but also on p53 status.

The implication of MT in cancer is controversial. An increase in MT level was reported in serum from patients with lymphoid leukemia, lung carcinoma, thyroid carcinoma, head and neck cancer or melanoma, ${ }^{24}$ whereas a decrease in MT level was reported in renal cancer, prostate or liver adenocarcinoma. $^{25-27}$ These discrepancies may result from the attributed or the sought role of MT in carcinogenesis, promoting tumor growth, tumor incidence or chemotherapy resistance. Given the high-sequence homology between 


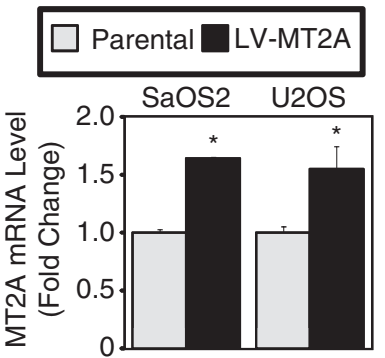

C

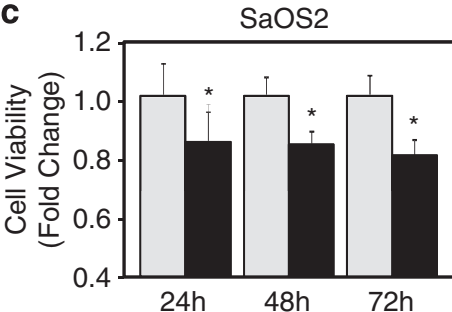

d
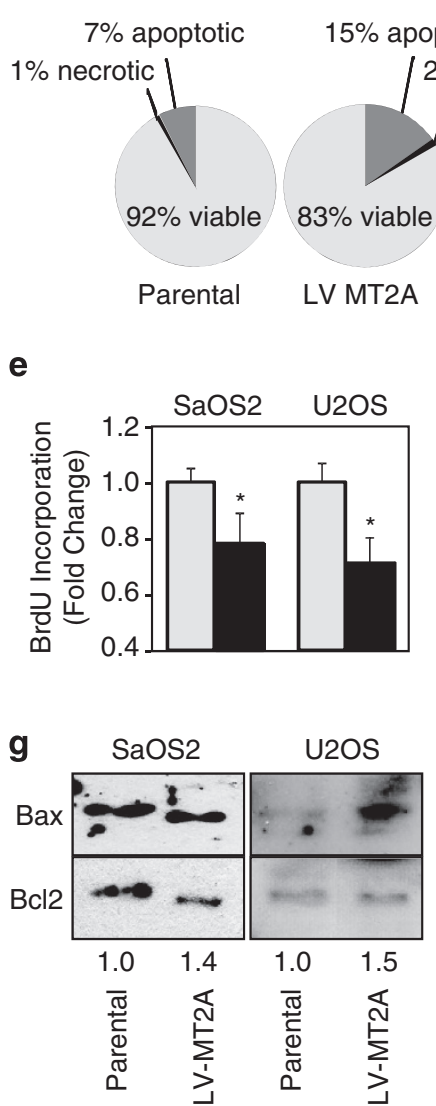
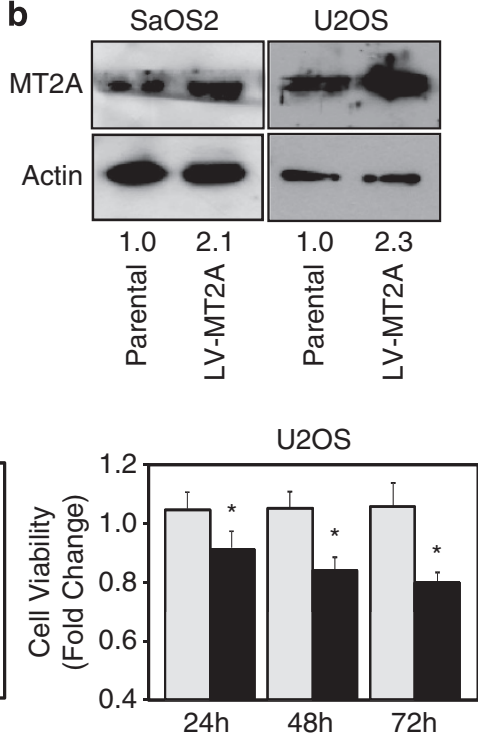

U2OS

$2 \%$ apoptotic $\quad 15 \%$ apoptotic

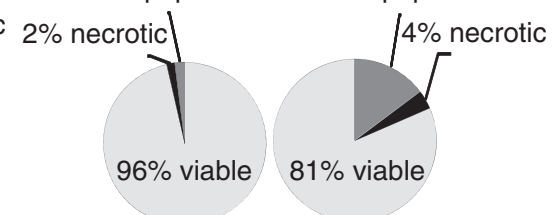

Parental LV-MT2A

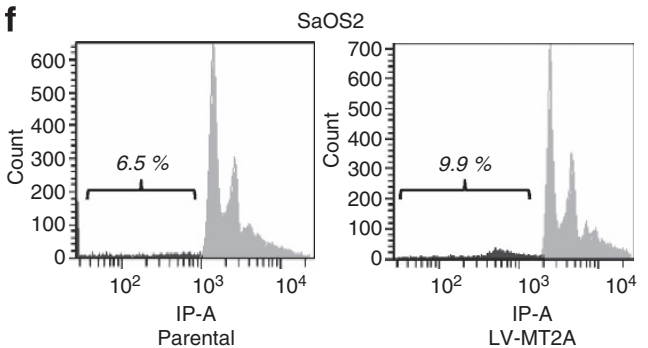

Figure 2 MT2A overexpression reduced osteosarcoma cell viability. SaOS2 and U2OS cell lines were transduced with an integrative lentiviral vector encoding the complete coding sequence of MT2A (LV-MT2A). (a) MT2A mRNA levels were evaluated by RT-qPCR. (b) MT2A protein levels were evaluated by western blot analysis. (c) Cell viability was evaluated using the MTT test. (d) Relative percentage of viable, necrotic and apoptotic cells were evaluated by acridine orange/ethidium bromide staining. (e) Cell replication was evaluated using a BrdU incorporation assay. (f) Apoptotic cell proportion (sub-G0/G1) was evaluated by flow cytometry. (g) Bax and Bcl-2 protein levels were evaluated by western blot analysis. Results are expressed as mean \pm S.D. and arbitrary units relative to parental cells. ${ }^{*} P<0.05$ versus untreated cells

different MT isoforms, none of previous studies have discriminated and estimated the expression levels among different MT family members or at least among MT I/II. In our model of bone tumor osteosarcoma, among all MTs, only the $2 \mathrm{~A}$ isoform has its expression level significantly increased by atorvastatin or simvastatin supplementation in osteosarcoma 


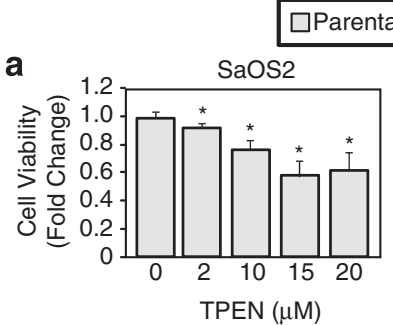

LV-MT2A

a

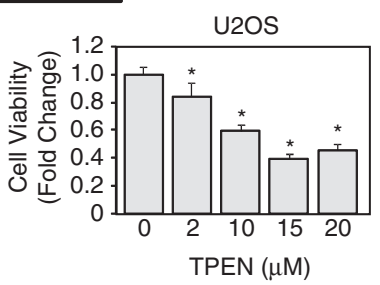

b
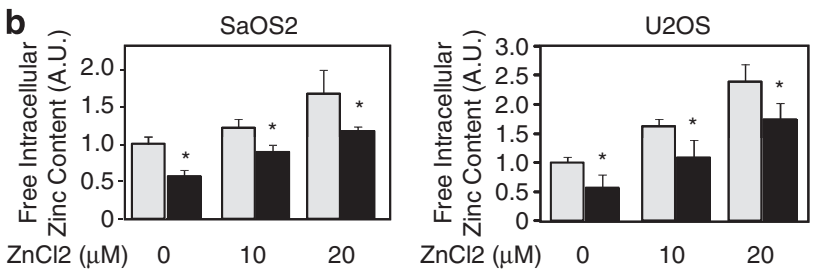

c

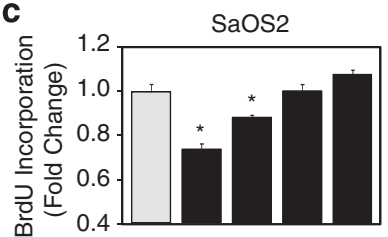

$\mathrm{ZnCl} 2(\mu \mathrm{M}) \quad 0 \quad 0 \quad 1 \quad 5 \quad 10$

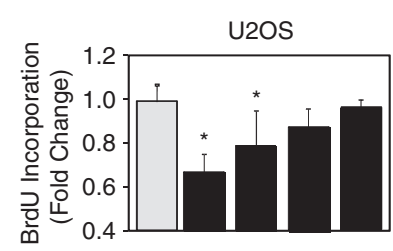

$\mathrm{ZnCl} 2(\mu \mathrm{M}) \quad 0 \quad 0 \quad 5 \quad 7.5 \quad 10$
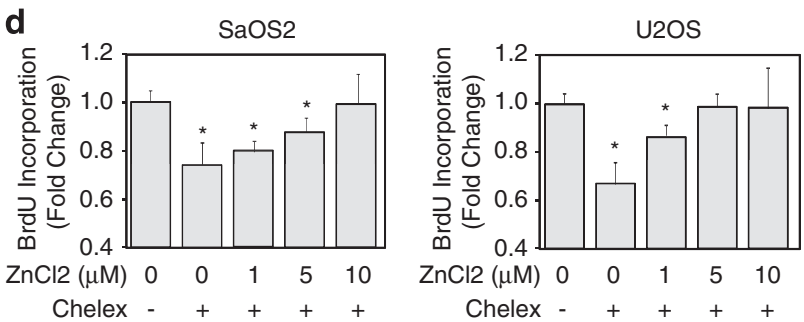

Figure 3 MT2A overexpression modulates osteosarcoma cell viability through zinc chelation. SaOS2 and U2OS parental cells were incubated with increasing doses of $\mathrm{Zn}$ chelator TPEN. (a) Cell viability was evaluated using the MTT test. (b) SaOS2 and U2OS parental and MT2A-overexpressing cells were incubated with increasing doses of $\mathrm{ZnCl}_{2}$. Free intracellular zinc content was evaluated by fluorimetry. (c) SaOS2 and U2OS MT2A-overexpressing cells were incubated with increasing doses of $\mathrm{ZnCl}_{2}$. Parental cells were maintained in normal medium. Cell replication was evaluated using a BrdU incorporation assay. (d) SaOS2 and U2OS parental cells were incubated in chelex-treated medium supplemented with increasing doses of $\mathrm{ZnCl}_{2}$. Cell replication was evaluated using a BrdU incorporation assay. Results are expressed as mean \pm S.D. ${ }^{*} P<0.05$ versus untreated cells

cells. We provide evidence of a direct stimulatory effect of statin supplementation on MT mRNA and protein levels. This suggests that osteosarcoma cells may rather use MT2A isoform in response to toxic agents such as statin. It would be interesting to evaluate the profile of MT and expression of isoforms rather than global MTI and/or MTII classes for more accurate discriminations for use as a marker of tumor differentiation, cell proliferation and invasiveness or prognosis predictor (reviewed in Costarelli et $a l^{35}$ ).

Zinc has a physiologically important role in bone homeostasis and has been demonstrated to have a stimulatory effect on osteoblastic bone formation and mineralization (reviewed in Yamaguchi ${ }^{28}$ ). Regulation of zinc ion homeostasis by MTs is well known. ${ }^{29-31}$ We showed here that statin dose-dependently reduce bioavailable intracellular zinc content in osteosarcoma cells, which is in agreement with different studies that report a decrease in zinc plasma levels from patients treated with statins. ${ }^{32-35}$ In the present study, we detected a rapid induction in MT2A expression during statin treatment and modulations of intracellular zinc content upon modulations of MT2A protein level. No significant modulation of expression was detected for zinc transporters consisting in importer (ZIP family) and exporter (ZnT family) proteins under statin treatment. It can be thus suggested that statins modulate zinc level through MT induction, but further experiments are needed to fully confirm this hypothesis.

Zinc supplementation has been shown to stimulate osteoblastic cell proliferation and differentiation. ${ }^{36,37}$ It has also been reported that MT2A level increased during rat mesenchymal stromal cell osteogenic differentiation. ${ }^{38}$ As expected, we found a modulation of both cell proliferation and differentiation in our models of osteosarcoma cells modified for MT2A compared with parental cells, and especially a strong inhibition of differentiation process without increased cell viability under MT2A silencing. Such inhibition of osteoblastic maturation or even a de-differentiation process could be highly beneficial and exploited as an adjuvant therapy, as current chemotherapies mostly target the proliferative cells. A possible effect of zinc chelation on cancer stem cells behavior or differentiation reprogramming may be considered but need much further investigations.

According to metastatic feature, we previously reported that statin supplementation inhibited osteosarcoma cell migration and invasion capacities. ${ }^{2}$ In the present study, we did not observe modification in cell motility or invasiveness of MT2Aoverexpressing cells or MT2A-silenced cells compared with osteosarcoma parental cells. We neither observed modulation in matrix metalloproteinase 2 activity, a zinc-dependent metalloproteinase involved in osteosarcoma cell invasion process. ${ }^{2}$ Taken together, these results reinforce the specificity of action of the different MT isoforms and suggest that MT2A isoform rather control cell viability than invasiveness or motility, at least in our osteosarcoma models.

Chemotherapy is the main treatment for osteosarcoma. Platinum-containing compounds such as cisplatin can be chelated by MT, which may render this drug ineffective in cancer cells (reviewed in Knipp ${ }^{39}$ ). We evaluated the response of our modified cells in term of viability and indeed observed a reduction in osteosarcoma cell sensitivity to cisplatin when MT2A was overexpressed. In contrast, silencing MT2A led to increased cisplatin toxicity. Even if the cis configuration is described as being required for its antitumor activity, ${ }^{40}$ we found that MT2A silencing can favor cytotoxic activity of both cisplatin and transplatin, thereby reinforcing the role of metal chelation in MT2A mechanism of action. These results have the limitations related to the in vitro approach but are promising for next in vivo validations. Platinum-based anticancer drugs are effective pharmaceuticals and are still the mostly used agents against malignancies. In addition, standard clinical protocols for osteosarcoma tumors combine cisplatin to other cytotoxic compounds, such as doxorubicin or vincristine, that do not contain metal ion and act through other molecular mechanisms. We found that MT2A overexpression or silencing can 


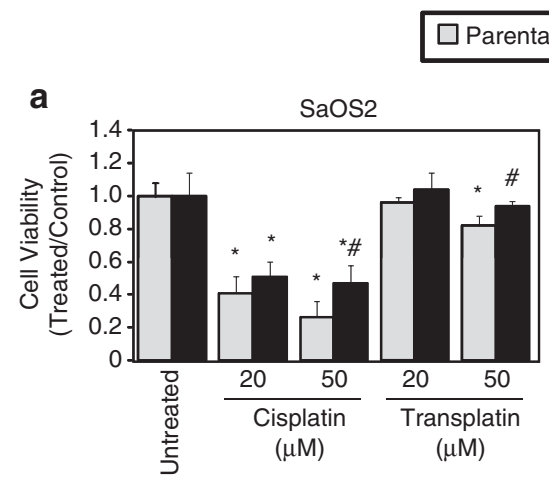

LV-MT2A
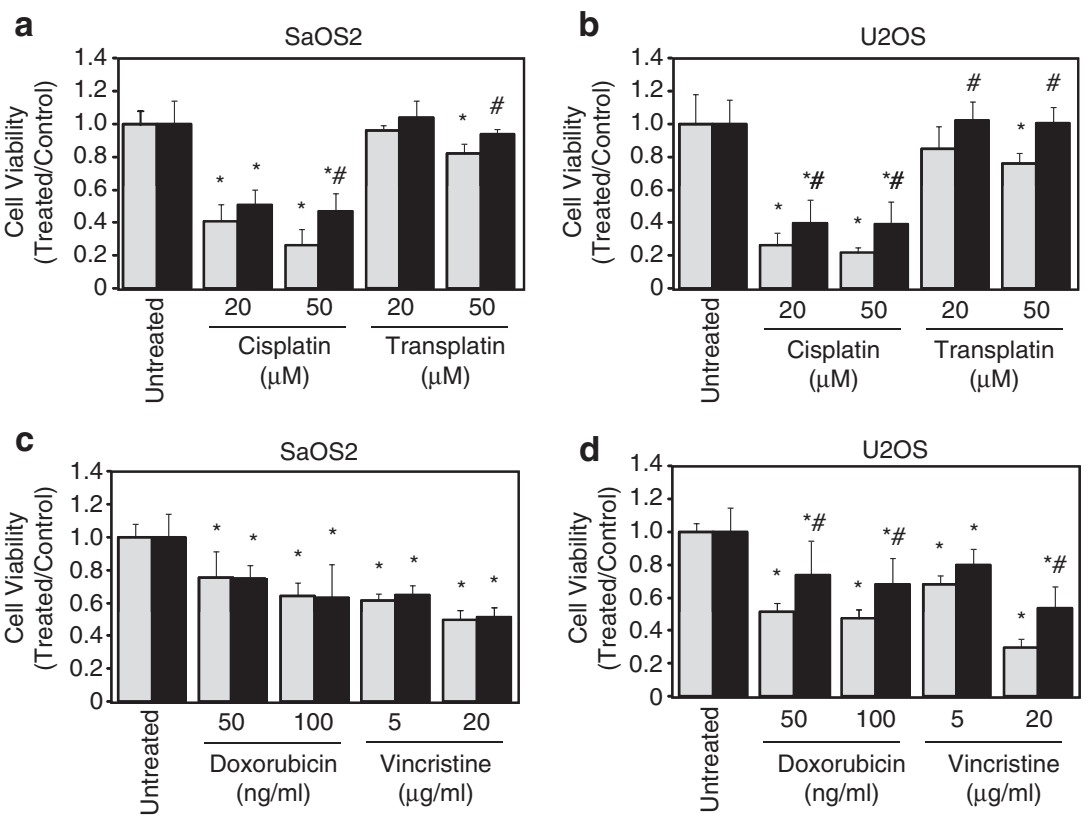

Figure 4 MT2A overexpression modulates cell response to cytotoxic agents. (a) SaOS2 parental and MT2A-overexpressing cells were incubated with or without cisplatin or transplatin for $48 \mathrm{~h}$. Cell viability was evaluated using the MTT test. (b) U2OS parental and MT2A-overexpressing cells were incubated with or without cisplatin or transplatin for $48 \mathrm{~h}$. Cell viability was evaluated using the MTT test. (c) SaOS2 parental and MT2A-overexpressing cells were incubated with or without doxorubicin or vincristine. Cell viability was evaluated using the MTT test. (d) U2OS parental and MT2A-overexpressing cells were incubated with or without doxorubicin or vincristine. Cell viability was evaluated using the MTT test. Results are expressed as mean \pm S.D. and as arbitrary units relative to corresponding untreated cells. ${ }^{*} P<0.05$ versus untreated cells; $\# P<0.05$ versus parental cells

also modulate osteosarcoma cell sensitivity to these compounds. These observations agree with results of other reports. ${ }^{41-43}$ A direct action through metal chelation cannot be considered, as no metal ion is present in these compounds. We rather suggest an indirect action through a key metaldependent factor. It has been described that zinc supplementation results in an increase of DNA damage induced by doxorubicin in an acute lymphoblastic leukemia cell line. ${ }^{44}$ The zinc-binding transcription factor p53 is essential for cell cycle regulation and apoptosis induced by genotoxic DNA damage. ${ }^{45,46}$ It has even been described as predictive factor of chemoresistance in breast cancer. ${ }^{47}$ In intact cells, p53 protein activity is crucially dependent on the availability of zinc ions, but MT can form a complex with $\mathrm{p} 53^{48,49}$ causing the removal of $\mathrm{Zn}^{2+}$ from p53 by their sulfhydryl groups. This leads p53 to adopt a 'mutant-like' form with inhibition of its binding to DNA ${ }^{50,51}$ and proteins. ${ }^{52}$ In our model, we found that overexpression of MT2A indeed reduces the pool of active form of p53. Alternative or additive mechanisms involving zinc-dependent factors other than p53 may be likely involved and they merit further investigation in future.

Some studies have reported that different isoforms of MT were upregulated in osteosarcoma versus non-malignant bone, ${ }^{20,21}$ but no data are available according to patient outcome or chemoresistance. In the present study, we determined the MT2A mRNA level in 17 patients suffering from osteosarcoma before neoadjuvant chemotherapy and found the highest levels of MT2A in biopsies from patients that will be poor responders compared with patients that are considered as good responders to chemotherapy. A marked difference was also observed in survival rate between the two groups, reinforcing the relation between treatment efficacy or response and patient outcome. These results strengthen the concept that MT2A level evaluation at diagnosis could help to predict tumor response to chemotherapy and thus patient outcome. The identification of individual isoforms seems to be a promising way in searching new prognostic markers in cancer at least for osteosarcoma. A previous study on biopsies of high-grade malignant osteosarcoma reports the absence of correlation between the expression level of MTs before chemotherapy and patient survival. ${ }^{53}$ However, in this study, quantification was conducted by immunohistochemistry on paraffin-embedded samples using an antibody recognizing all isoforms of MT-I and MT-II subgroups, which may had reduce sensitivity of the measurement. Determining the expression of individual isoforms of human MT proteins is problematic because of the high-sequence homology that is present among those family members (up to over $90 \%$ ). ${ }^{54}$ To overcome this issue, we proposed a detection of MTs isoforms by quantitative RT-PCR using specific primers, which was based on the isolation of RNA from clinical samples.

In our model, we showed that the MT2A expression level is correlated with chemotherapy resistance in osteosarcoma cells. We can thus hypothesize that besides their high homology, each isoform may have a specific cellular role. This also led us to hypothesize that targeting specific isoform could be possibly helpful to improve chemo-sensitivity. 


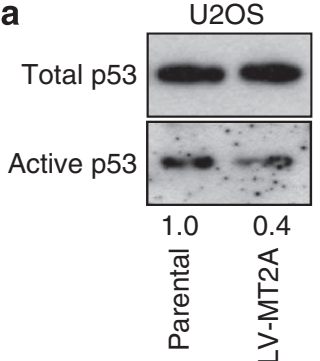

C

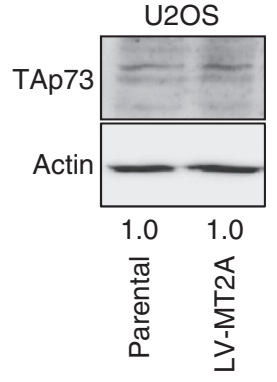

e

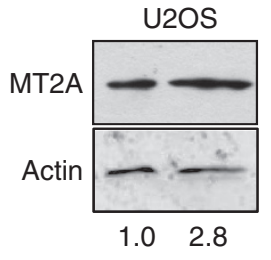

Doxorubicin b

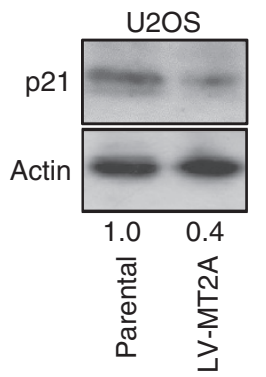

d

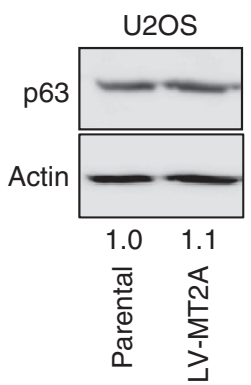

f

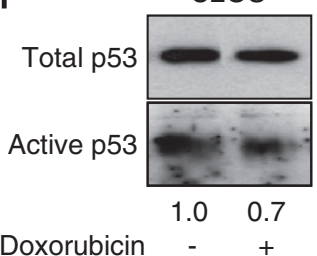

Figure 5 MT2A modulates p53 conformation-dependent activity. (a) Relative content of active form of P53 was evaluated by immunoprecipitation using a conformational-dependent antibody. (b) P21 protein levels were evaluated in U2OS parental and MT2A-overexpressing cells by western blot analysis. (c,d) P73 and $\mathrm{P} 63$ protein levels were evaluated in U2OS parental and MT2A-overexpressing cells by western blot analysis. (e) MT2A protein levels were evaluated in U2OS cells incubated in the presence or absence of doxorubicin $(100 \mathrm{ng} / \mathrm{ml})$. (f) Relative content of active form of P53 was evaluated by immunoprecipitation using a conformational-dependent antibody

Although no specific MT inhibitor has yet been described, MT2A might be considered as a biomarker for chemosensitivity of osteosarcoma tumors.

\section{Materials and Methods}

Cell culture. Human osteosarcoma cell lines SaOS2 and U2OS (American Type Culture Collection, Rockville, MD, USA) were routinely maintained in Dulbecco's-modified Eagle's medium (PAA Laboratories, Velizy-Villacoublay, France) supplemented with $10 \%$ heat-inactivated fetal calf serum (FCS; PAA Laboratories), $10000 \mathrm{U} / \mathrm{ml} \mathrm{L-glutamine} \mathrm{and} 10000 \mu \mathrm{g} / \mathrm{ml}$ penicillin/streptomycin, at $37^{\circ} \mathrm{C}$ under $5 \% \mathrm{CO}_{2} / 95 \%$ air in an humidified incubator.

Reagents. All reagents were obtained from Sigma-Aldrich (Lyon, France). Zincdepleted medium was prepared by incubating FCS with 10\% Chelex-100 (under overnight agitation) before addition to medium. Atorvastatin and transplatin were solubilized in dimethyl sulfoxide at concentrations of 10 and $15 \mathrm{mM}$, respectively. Doxorubicin, cisplatin and vincristine were solubilized in $\mathrm{H}_{2} \mathrm{O}$ at concentrations of $10 \mathrm{mg} / \mathrm{ml} ; 25 \mathrm{mM}$ and $1 \mathrm{mg} / \mathrm{ml}$, respectively.

Expression microarrays. RNA from SaOS2 cells incubated with or without atorvastatin $(10 \mu \mathrm{M})$ for 6,15 or $24 \mathrm{~h}$ were labeled and hybridized on pan-genomic microarrays containing the human RNG/MRC oligonucleotide collection. ${ }^{4}$

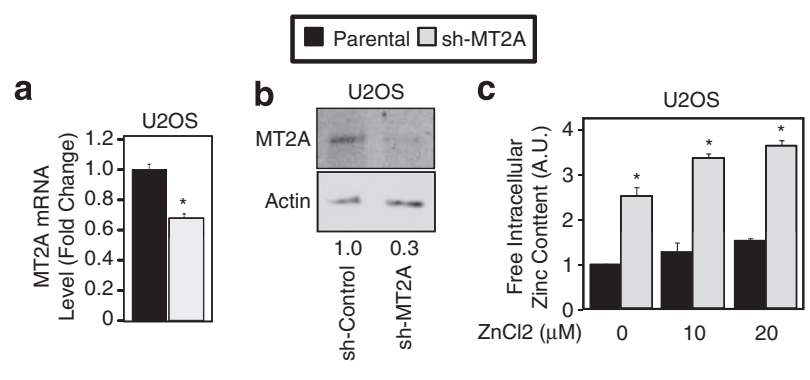

d
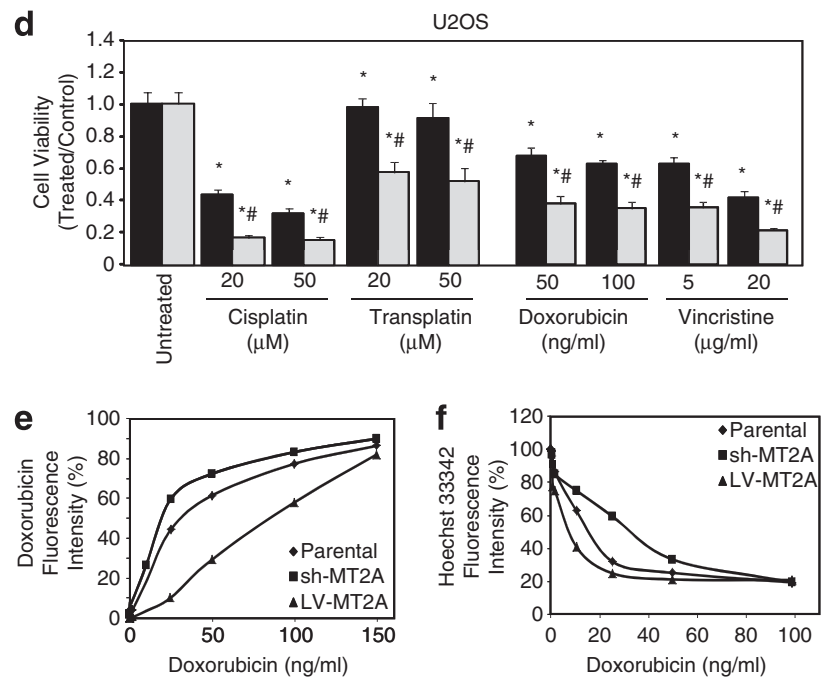

Figure 6 MT2A silencing amplifies osteosarcoma cell response to cytotoxic agents. U2OS cell line was transduced with an integrative lentiviral vector encoding a specific shRNA sequence targeting MT2A (sh-MT2A). (a) MT2A mRNA levels were evaluated by RT-qPCR in U2OS parental and MT2A-silenced cells. (b) MT2A protein levels were evaluated by western blot analysis in U2OS parental and MT2Asilenced cells. (c) U2OS parental and MT2A-silenced cells were incubated with increasing doses of $\mathrm{ZnCl}_{2}$. Free intracellular zinc content was evaluated by fluorimetry. (d) U2OS parental and MT2A-silenced cells were incubated with or without cisplatin, transplatin, doxorubicin or vincristine for $48 \mathrm{~h}$. Cell viability was evaluated using the MTT test. (e) Relative amounts of doxorubicin combined to DNA were evaluated by flow cytometry into parental, silenced and overexpressing U2OS cells. (f) Relative amounts of Hoechst 33342 bound to DNA were evaluated by flow cytometry into parental, silenced and overexpressing U2OS cells. Results are expressed as mean \pm S.D. ${ }^{\star} P<0.05$ versus untreated cells; $\# P<0.05$ versus parental cells

Lentiviral constructs and cell transduction. The pIRESneo2 plasmid containing the human MT2A complete coding sequence was kindly provided by Dr. VanderWesthuizen (North West University, Potchefstroom, South Africa). This coding sequence was cloned into HIV1-derived vector TRIP between the BamH1 and Xho1 sites. Virion particles were produced by transfection of HEK293T cells. ${ }^{55}$ Ready-to-use lentiviral particles containing vector-encoding human MT2A shRNA were purchased from Santa Cruz Biotechnology (Santa Cruz, CA, USA).

Cell proliferation. Cell proliferation rate was evaluated by BrdU assay using the Kit Biotrak ELISA System (GE Healthcare, Orsay, France). Cells were seeded at $15000 \mathrm{cell} / \mathrm{s} / \mathrm{cm}^{2}$ in complete medium. After $48 \mathrm{~h}, \mathrm{BrdU}(10 \mu \mathrm{M})$ was added to the medium for the last $2 \mathrm{~h}$ of culture. Six replicates were used for each condition and experiments were repeated twice.

Cell viability. Cell viability was assessed after $48 \mathrm{~h}$ by the MTT assay as previously described ${ }^{56}$ Experiments were repeated three times with six replicates for each condition.

Acridine orange/ethidium bromide staining. A double staining with ethidium bromide and acridine orange was performed as previously described. ${ }^{56}$ 


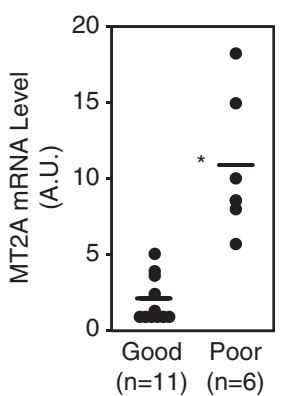

b

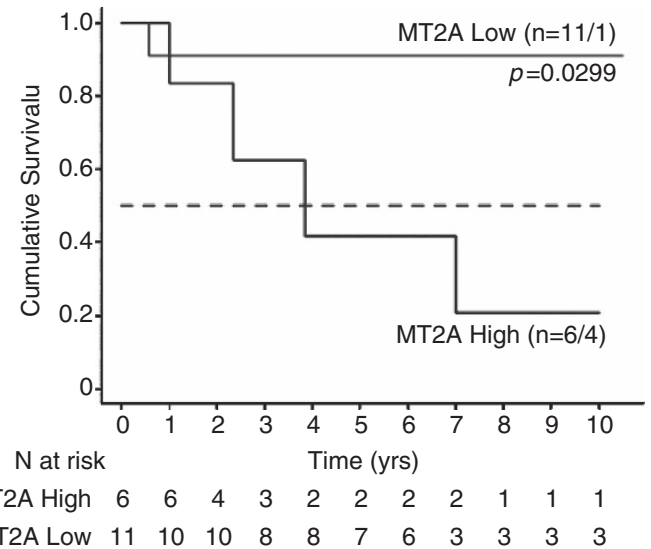

Figure 7 Prognostic value of MT2A mRNA expression in osteosarcoma. (a) MT2A mRNA levels were evaluated by RT-qPCR, in biopsies from good and poor responders. Results were expressed as arbitrary unit (AU). Mean values of each group are indicated as black bars. ${ }^{*} P<0.05$ versus untreated cells. (b) Kaplan-Meier survival curves from patients with low MT2A mRNA level or patients with highest MT2A mRNA level

Cell cycle analysis by flow cytometry. Cell cycle phases were assessed by propidium iodide staining and flow cytometric analysis was carried out with FACS Canto II cytometer (Becton Dickinson, Le Pont-De-Claix, France) using standard methods. Briefly, cells were collected with trypsin-EDTA and fixed in cold $70 \%$ ethanol. Cells were then incubated in PBS supplemented with $0.1 \%$ Triton-X 100, $40 \mathrm{mg} / \mathrm{ml}$ RNase A and $8 \mu \mathrm{g} / \mathrm{ml}$ propidium iodide for $60 \mathrm{~min}$ at RT. The experiment was repeated twice.

Competitive fluorochrome staining analysis by flow cytometry. Doxorubicin uptake in DNA was evaluated directly and indirectly through competitive bis-benzimide staining. Cells were incubated with or without increasing concentrations of doxorubicin for $24 \mathrm{~h}$ and then with $5 \mu \mathrm{g} / \mathrm{ml}$ Hoechst 33342 for $90 \mathrm{~min}$. After PBS washes, cells were harvested by trypsin, suspended to a concentration of $3 \times 10^{5} \mathrm{cells} / \mathrm{ml}$ in ice-cold PBS and analyzed by flow cytometry. Both doxorubicin ( $\lambda$ ex $488 \mathrm{~nm}, \lambda \mathrm{em} 606 \mathrm{~nm}$ ) and DNA complexed Hoechst ( $\lambda \mathrm{ex}$

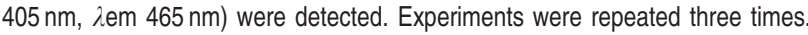

Intracellular zinc concentration. The zinc concentration was evaluated by intracellular fluorimetry using the specific probe: zinquin (ethyl-[2-methyl-8-ptoluenesulphonamido-6-quinolyloxy]-acetate; Sigma-Aldrich). Cells were rinsed once with PBS and then incubated in PBS $/ 1 \% \mathrm{BSA} / 25 \mu \mathrm{M}$ zinquin for $45 \mathrm{~min}$ at $37^{\circ} \mathrm{C}$ in the dark. Cells were then centrifuged at $2000 \times g$ for $5 \mathrm{~min}$ and suspended in PBS. Fluorescence was measured using $\lambda$ ex $368 \mathrm{~nm}$ and $\lambda$ em $490 \mathrm{~nm}$. The maximal fluorescence, reflecting the total amount of intracellular zinc, was determined after the addition of saponin $(0.25 \%)$. Assay was performed three times with 5-6 replicates for each condition.

RNA extraction and reverse transcription. Total RNA were isolated from cell cultures by phenol/chloroform extraction using Trizol Reagent (Invitrogen, Cergy-Pontoise, France) and solubilized in $\mathrm{H}_{2} \mathrm{O}$ supplemented with RNase inhibitor (Ambion, Courtaboeuf, France). Three micrograms of RNA were incubated in a buffer containing reverse transcriptase MMLV (Moloney Murine Leukemia Virus, $10 \mathrm{U})$, DTT $(3 \mathrm{mM})$, oligodT primers $(0.05 \mathrm{mg} / \mathrm{ml})$ and dNTPs (1 mM) for $90 \mathrm{~min}$ at $37^{\circ} \mathrm{C}$. A final step of inactivation of the enzyme is carried out at $95^{\circ} \mathrm{C}$ for $5 \mathrm{~min}$.

Chemonaive cell subpopulations were isolated as previously described from newly diagnosed patients ${ }^{57}$ and total RNA was extracted as previously described. Among 17 patients available for follow-up, the tumors were located in the proximal tibia in 10 patients, in the distal femur in 7 patients and in clavicle in 1 patient. After surgical resection, the percentage of histologically viable tumor was scored. ${ }^{58}$ If the percentage of necrosis was $<90 \%$, the patient was considered to be a poor responder, and if $>90 \%$ of necrosis was found, the patient was considered as a good responder.

Quantitative PCR amplification. The expression level of mRNA encoding the MT2A was evaluated and normalized relative to that of GAPDH. The amplification was performed as previously described ${ }^{4}$ using SYBR Green PCR kit (ABgene, Courtabouef Cedex, France) and pairs of specific primers: GAPDH sense $5^{\prime}$-CGAGATCCCTCCAAAATCAA-3' forward $5^{\prime}$-TGTGGTCAT GAGTCCTTCCA-3'; MT2A sense $5^{\prime}$-TGCACCTCCTGCAAGAAA-3' forward 5'-CAGCAGCTGCACTTGTCC-3'.

Western blot and immunoprecipitation. Proteins from total cell lysates were resolved by sodium dodecyl sulfate-polyacrylamide gel electrophoresis as previously described. ${ }^{4}$ Anti- $\beta$-actin was purchased from Sigma-Aldrich, and anti-p21, anti-p53 and anti-p63 were purchased from Santa Cruz Biotechnology. Anti-MT2A was purchased from Abcam (Cambridge, UK) and anti-p73 from Calbiochem (Nottingham, UK).

For immunoprecipitation, aliquots of clarified total cell lysates $(250 \mu \mathrm{g})$ were incubated overnight under weak agitation at $4^{\circ} \mathrm{C}$ with $2 \mu \mathrm{g}$ specific antibody and $20 \mu \mathrm{l}$ Adembeads Protein AG (Ademtech, Pessac, France). Components of the bound immune complex were eluted according to the manufacturer's recommendations and analyzed by sodium dodecyl sulfate-polyacrylamide gel electrophoresis as above. Anti-p53 antibodies PAb1620 and PAb240 were purchased from Abcam.

Statistical analysis. Comparisons between in vitro data were performed using the two-factor analysis of variance with a minimal level of $P<0.05$ considered to be significant. Clinical samples data were analyzed using non-parametric Mann-Whitney test with $P<0.05$ considered to be significant.

\section{Conflict of Interest}

The authors declare no conflict of interest.

Acknowledgements. $\mathrm{NH}$ is a recipient of a $\mathrm{PhD}$ award from the Ministère de la Recherche (Paris, France). FL and AP-G are supported by AECC project, UTE project FIMA agreement, RTICCC C03/10, PI042284 and PI10/01580 grants. This work was supported in part by Inserm. We warmly thank the support of the NiceSophia Antipolis Transcriptome Platform of the Marseille-Nice Genopole. We thank Prof Van der Westhuizen (North West University, Potchefstroom, South Africa) for providing the MT2A-pIRES vector. We thank Dr. Alsafadi (Inserm U981, Villejuif, France) for her helpful discussion and technical support in p53-family analyses. We thank Mrs. Marty, Miss. Chantrenne and Dr. Ostertag (Inserm U606, Paris, France) and Mrs. Goubar (Inserm U981, Villejuif, France) for their technical contributions.

1. Fromigue O, Hay E, Modrowski D, Bouvet S, Jacquel A, Auberger $P$ et al. RhoA GTPase inactivation by statins induces osteosarcoma cell apoptosis by inhibiting p42/p44-MAPKsBcl-2 signaling independently of BMP-2 and cell differentiation. Cell Death Differ 2006; 13: 1845-1856.

2. Fromigue O, Hamidouche Z, Marie PJ. Blockade of the RhoA-JNK-c-Jun-MMP2 cascade by atorvastatin reduces osteosarcoma cell invasion. J Biol Chem 2008; 283: 30549-30556.

3. Fromigue O, Hamidouche Z, Marie PJ. Statin-induced inhibition of 3-hydroxy-3-methyl glutaryl coenzyme A reductase sensitizes human osteosarcoma cells to anticancer drugs. J Pharmacol Exp Ther 2008; 325: 595-600.

4. Fromigue $\mathrm{O}$, Hamidouche $Z$, Vaudin $\mathrm{P}$, Lecanda F, Patino A, Barbry P et al. CYR61 downregulation reduces osteosarcoma cell invasion, migration, and metastasis. J Bone Miner Res 2011; 26: 1533-1542.

5. Coyle P, Philcox JC, Carey LC, Rofe AM. Metallothionein: the multipurpose protein Cell Mol Life Sci 2002; 59: 627-647. 
6. Ruttkay-Nedecky B, Nejdl L, Gumulec J, Zitka O, Masarik M, Eckschlager T et al. The role of metallothionein in oxidative stress. Int J Mol Sci 2013; 14: 6044-6066.

7. Laukens D, Waeytens A, De Bleser P, Cuvelier C, De Vos M. Human metallothionein expression under normal and pathological conditions: mechanisms of gene regulation based on in silico promoter analysis. Crit Rev Eukaryot Gene Exp 2009; 19 : 301-317.

8. Thirumoorthy N, Shyam Sunder A, Manisenthil Kumar K, Senthil Kumar M, Ganesh G, Chatterjee M. A review of metallothionein isoforms and their role in pathophysiology. World J Surg Oncol 2011; 9: 54

9. Aschner M. The functional significance of brain metallothioneins. FASEB $J$ 1996; 10: 1129-1136.

10. Uchida Y, Gomi F, Masumizu T, Miura Y. Growth inhibitory factor prevents neurite extension and the death of cortical neurons caused by high oxygen exposure through hydroxyl radical scavenging. J Biol Chem 2002; 277: 32353-32359.

11. Jacob C, Maret W, Vallee BL. Control of zinc transfer between thionein, metallothionein, and zinc proteins. Proc Natl Acad Sci USA 1998; 95: 3489-3494.

12. Maret $\mathrm{W}$, Vallee BL. Thiolate ligands in metallothionein confer redox activity on zinc clusters. Proc Natl Acad Sci USA 1998; 95: 3478-3482.

13. Jiang $L J$, Maret $W$, Vallee BL. The glutathione redox couple modulates zinc transfer from metallothionein to zinc-depleted sorbitol dehydrogenase. Proc Natl Acad Sci USA 1998; 95: 3483-3488.

14. Sabolić I, Breljak D, Skarica M, Herak-Kramberger CM. Role of metallothionein in cadmium traffic and toxicity in kidneys and other mammalian organs. Biometals 2010; 23: 897-926.

15. Kelley SL, Basu A, Teicher BA, Hacker MP, Hamer DH, Lazo JS. Overexpression of metallothionein confers resistance to anticancer drugs. Science 1988; 241: 1813-1815.

16. Kasahara K, Fujiwara Y, Nishio K, Ohmori T, Sugimoto Y, Komiya K et al. Metallothionein content correlates with the sensitivity of human small cell lung cancer cell lines to cisplatin. Cancer Res 1991; 51: 3237-3242.

17. Nakano M, Sogawa CA, Sogawa N, Mishima K, Yamachika E, Mizukawa N et al. Expression pattern of cisplatin-induced metallothionein isoforms in squamous cell carcinoma. Anticancer Res 2003; 23: 299-303.

18. Choi CH, Cha YJ, An CS, Kim KJ, Kim KC, Moon SP et al. Molecular mechanisms of heptaplatin effective against cisplatin-resistant cancer cell lines: less involvement of metallothionein. Cancer Cell Int 2004; 4: 6

19. Surowiak P, Materna V, Maciejczyk A, Pudełko M, Markwitz E, Spaczyński M et al. Nuclear metallothionein expression correlates with cisplatin resistance of ovarian cancer cells and poor clinical outcome. Virchows Arch 2007; 450: 279-285.

20. Krizkova S, Masarik M, Majzlik P, Kukacka J, Kruseova J, Adam $V$ et al. Serum metallothionein in newly diagnosed patients with childhood solid tumours. Acta Biochim Pol 2010; $57:$ 561-566.

21. Endo-Munoz L, Cumming A, Sommerville S, Dickinson I, Saunders NA. Osteosarcoma is characterised by reduced expression of markers of osteoclastogenesis and antigen presentation compared with normal bone. Br J Cancer 2010; 103: 73-81.

22. Sturm I, Bosanquet AG, Hermann S, Güner D, Dörken B, Daniel PT. Mutation of p53 and consecutive selective drug resistance in B-CLL occurs as a consequence of prior DNAdamaging chemotherapy. Cell Death Differ 2003; 10: 477-484

23. Lynes MA, Kang YJ, Sensi SL, Perdrizet GA, Hightower LE. Heavy metal ions in normal physiology, toxic stress, and cytoprotection. Ann N Y Acad Sci 2007; 1113: 159-172.

24. Eckschlager T, Adam V, Hrabeta J, Figova K, Kizek R. Metallothioneins and cancer. Curr Protein Pept Sci 2009; 10: 360-375.

25. Ishii K, Usui S, Yamamoto $H$, Sugimura $Y$, Tatematsu M, Hirano K. Decreases of metallothionein and aminopeptidase $\mathrm{N}$ in renal cancer tissues. J Biochem 2001; 129: 253-258.

26. Huang GW, Yang LY. Metallothionein expression in hepatocellular carcinoma. World $J$ Gastroenterol 2002; 8: 650-653.

27. Wei H, Desouki MM, Lin S, Xiao D, Franklin RB, Feng P. Differential expression of metallothioneins (MTs) 1,2 , and 3 in response to zinc treatment in human prostate normal and malignant cells and tissues. Mol Cancer 2008; $7: 7$.

28. Yamaguchi M. Role of nutritional zinc in the prevention of osteoporosis. Mol Cell Biochem 2010; 338: 241-254.

29. Gumulec J, Masarik M, Krizkova S, Adam V, Hubalek J, Hrabeta J et al. Insight to physiology and pathology of zinc(II) ions and their actions in breast and prostate carcinoma. Curr Med Chem 2011; 18: 5041-5051.

30. Zitka O, Ryvolova M, Hubalek J, Eckschlager T, Adam V, Kizek R. From amino acids to proteins as targets for metal-based drugs. Curr Drug Metab 2012; 13: 306-320.

31. Krizkova S, Ryvolova M, Hrabeta J, Adam V, Stiborova M, Eckschlager T et al. Metallothioneins and zinc in cancer diagnosis and therapy. Drug Metab Rev 2012; 44 287-301.

32. Leonhardt W, Kurktschiev T, Meissner D, Lattke P, Abletshauser C, Weidinger G et al. Effects of fluvastatin therapy on lipids, antioxidants, oxidation of low density lipoproteins and trace metals. Eur J Clin Pharmacol 1997; 53: 65-69.
33. Yilmaz MI, Baykal Y, Kilic M, Sonmez A, Bulucu F, Aydin A et al. Effects of statins on oxidative stress. Biol Trace Elem Res 2004; 98: 119-127.

34. Ghayour-Mobarhan M, Lamb DJ, Taylor A, Vaidya N, Livingstone C, Wang T et al. Effect of statin therapy on serum trace element status in dyslipidaemic subjects. J Trace Elem Med Biol 2005; 19: 61-67.

35. Costarelli L, Muti E, Malavolta M, Giacconi R, Cipriano C, Sartini D et al. Modulation of genes involved in zinc homeostasis in old low-grade atherosclerotic patients under effects of HMG-CoA reductase inhibitors. Rejuvenation Res 2008; 11: 287-291.

36. Nagata M, Lönnerdal B. Role of zinc in cellular zinc trafficking and mineralization in a murine osteoblast-like cell line. J Nutr Biochem 2011; 22: 172-178.

37. Seo HJ, Cho YE, Kim T, Shin HI, Kwun IS. Zinc may increase bone formation through stimulating cell proliferation, alkaline phosphatase activity and collagen synthesis in osteoblastic MC3T3-E1 cells. Nutr Res Pract 2010; 4: 356-361.

38. Dohi Y, Shimaoka H, Ikeuchi M, Ohgushi H, Yonemasu K, Minami T. Role of metallothionein isoforms in bone formation processes in rat marrow mesenchymal stem cells in culture. Biol Trace Elem Res 2005; 104: 57-70.

39. Knipp M. Metallothioneins and platinum(II) anti-tumor compounds. Curr Med Chem 2009; 16: $522-537$.

40. Zamble DB, Lippard SJ. Cisplatin and DNA repair in cancer chemotherapy. Trends Biochem Sci 1995; 20: 435-439.

41. Webber MM, Rehman SM, James GT. Metallothionein induction and deinduction in human prostatic carcinoma cells: relationship with resistance and sensitivity to adriamycin. Cancer Res 1988; 48: 4503-4508.

42. Volm M, Koomägi R, Mattern J, Efferth T. Protein expression profiles indicative for drug resistance of non-small cell lung cancer. Br J Cancer 2002; 87: 251-257.

43. Yap X, Tan HY, Huang J, Lai Y, Yip GW, Tan PH et al. Over-expression of metallothionein predicts chemoresistance in breast cancer. J Pathol 2009; 217: 563-570.

44. Wysokinski D, Blasiak J, Wozniak K. Zinc differentially modulates DNA damage induced by anthracyclines in normal and cancer cells. Exp Oncol 2012; 34: 327-331.

45. Vogelstein B, Lane D, Levine AJ. Surfing the p53 network. Nature 2000; 408: 307-310.

46. Vousden KH, Lu X. Live or let die: the cell's response to p53. Nat Rev Cancer 2002; 594-604.

47. Knappskog S, Lønning PE. P53 and its molecular basis to chemoresistance in breast cancer. Expert Opin Ther Targets 2012; 16(Suppl 1): S23-S30.

48. Abdel-Mageed AB, Agrawal KC. Activation of nuclear factor kappaB: potential role in metallothionein-mediated mitogenic response. Cancer Res 1998; 58: 2335-2338.

49. Ostrakhovitch EA, Olsson PE, Jiang S, Cherian MG. Interaction of metallothionein with tumor suppressor p53 protein. FEBS Lett 2006; 580: 1235-1238.

50. Xia N, Liu L, Yi X, Wang J. Studies of interaction of tumor suppressor p53 with apo-MT using surface plasmon resonance. Anal Bioanal Chem 2009; 395: 2569-2575.

51. Méplan C, Verhaegh G, Richard MJ, Hainaut P. Metal ions as regulators of the conformation and function of the tumour suppressor protein p53: implications for carcinogenesis. Proc Nutr Soc 1999; 58: 565-571.

52. Wang J, Yang J. Interaction of tumor suppressor p53 with DNA and proteins. Curr Pharm Biotechnol 2010; 11: 122-127.

53. Shnyder SD, Hayes AJ, Pringle J, Archer CW. P-glycoprotein and metallothionein expression and resistance to chemotherapy in osteosarcoma. Br J Cancer 1998; 78 : 757-759.

54. Sewell AK, Jensen LT, Erickson JC, Palmiter RD, Winge DR. Bioactivity of metallothionein3 correlates with its novel beta domain sequence rather than metal binding properties. Biochemistry 1995; 34: 4740-4747

55. Hamidouche Z, Haÿ E, Vaudin P, Charbord P, Schüle R, Marie PJ et al. FHL2 mediates dexamethasone-induced mesenchymal cell differentiation into osteoblasts by activating Wnt/beta-catenin signaling-dependent Runx2 expression. FASEB J 2008; 22: 3813-3822.

56. Fromigue $\mathrm{O}$, Lagneaux L, Body JJ. Bisphosphonates induce breast cancer cell death in vitro. J Bone Miner Res 2000; 15: 2211-2221.

57. Patiño-García A, Zalacain M, Folio C, Zandueta C, Sierrasesúmaga L, San Julián M et al Profiling of chemonaive osteosarcoma and paired-normal cells identifies EBF2 as a mediator of osteoprotegerin inhibition to tumor necrosis factor-related apoptosis-inducing ligand-induced apoptosis. Clin Cancer Res 2009; 15: 5082-5091.

58. Huvos AG, Rosen G, Marcove RC. Primary osteogenic sarcoma: pathologic aspects in 20 patients after treatment with chemotherapy en bloc resection, and prosthetic bone replacement. Arch Pathol Lab Med 1977; 101: 14-18.

(c) (i) (s) $\odot$ Cell Death and Disease is an open-access journal published by Nature Publishing Group. This work is licensed under a Creative Commons Attribution-NonCommercialNoDerivs 3.0 Unported License. To view a copy of this license, visit http://creativecommons.org/licenses/by-nc-nd/3.0/ 